\title{
The Southern Annular Mode: a comparison of indices
}

\author{
M. Ho, A. S. Kiem, and D. C. Verdon-Kidd \\ Environmental and Climate Change Research Group, School of Environmental and Life Sciences, Faculty of Science and \\ Information Technology, University of Newcastle, Newcastle, Australia
}

Correspondence to: M. Ho (michelle.ho@uon.edu.au)

Received: 15 June 2011 - Published in Hydrol. Earth Syst. Sci. Discuss.: 1 August 2011

Revised: 6 March 2012 - Accepted: 14 March 2012 - Published: 26 March 2012

\begin{abstract}
The Southern Annular Mode (SAM) has been identified as a climate mechanism with potentially significant impacts on the Australian hydroclimate. However, despite the identification of relationships between SAM and Australia's hydroclimate using certain data sets, and focussed on certain time periods, the association has not been extensively explored and significant uncertainties remain. One reason for this is the existence of numerous indices, methods and data sets by which SAM has been approximated. In this paper, the various SAM definitions and indices are reviewed and the similarities and discrepancies are discussed, along with the strengths and weaknesses of each index development approach. Further, the sensitivity of the relationship between SAM and Australian rainfall to choice of SAM index is quantified and recommendations are given as to the most appropriate index to use when assessing the impacts of the SAM on Australia's hydroclimate. Importantly this study highlights the need to consider the impact that the choice of SAM index, and data set used to calculate the index, has on the outcomes of any SAM attribution study.
\end{abstract}

\section{Introduction}

It is well known that Australia's hydroclimate exhibits significant spatial and temporal variability (e.g. Chiew et al., 1998; Franks and Kuczera, 2002; Nicholls, 2004; Verdon et al., 2004; Verdon-Kidd and Kiem, 2009a). Much of this variability has been linked to ocean-atmospheric processes occurring in the Pacific and Indian Ocean, specifically the El Niño/Southern Oscillation (ENSO) (McBride and Nicholls, 1983; Drosdowsky, 1993; Kiem and Franks, 2001; Meyers et al., 2007), the Interdecadal Pacific Oscillation (IPO) (Power et al., 1999; Kiem et al., 2003; Kiem and Franks, 2004; Risbey et al., 2009) and the Indian Ocean Dipole (IOD) (Saji and Yamagata, 2003; Verdon and Franks, 2005; Meyers et al., 2007; Risbey et al., 2009). Other studies have also identified relationships between the Southern Annular Mode (SAM) and Australia's hydroclimate (e.g. Hendon et al., 2007), with Gillett et al. (2006) and Meneghini et al. (2007) suggesting that the SAM's influence on Australian hydroclimatology may be equal or even greater than the influence of ENSO or IOD in certain regions during particular seasons and epochs. Recent papers (e.g. Murphy and Timbal, 2008; Risbey et al., 2009; Gallant et al., 2011) provide a comprehensive summary of the key ocean-atmospheric processes driving Australian hydroclimatic variability and from these review papers it is clear that, in comparison with ENSO and IOD, very little is known about the SAM and its relationship with Australian hydroclimate. The literature that does exist on SAM and its teleconnections also reveals inconsistencies relating to (a) how SAM is defined, (b) the index used to represent SAM, (c) the data set used to calculate each SAM index and (d) how the various phases of SAM should be classified. This confusion as to how to approximate (i.e. which SAM index to use) and classify SAM for hydroclimatic impact analysis, combined with the lack of research focusing on climate drivers originating from the Southern Ocean, has led to a significant knowledge gap in our understanding of how much of Australia's hydroclimatic variability can be attributed to SAM. Furthermore, although preliminary investigations have been conducted (e.g. L'Heureux and Thompson, 2006), it is not yet clearly understood how SAM interacts with other large-scale climate drivers (e.g. ENSO, IOD, IPO) and local-scale synoptic weather patterns known to influence Australian hydroclimatology (Gallant et al., 2011; Kiem and Verdon-Kidd, 2011).

Importantly, anomalous SAM behaviour has been linked to the recent protracted droughts in south-west Western Australia (SWWA) (Cai and Cowan, 2006) and south-east Australia (SEA) (Murphy and Timbal, 2008; Verdon-Kidd and Kiem, 2009a; Gallant et al., 2011) that is projected to become more frequent under global warming (Cai et al., 2005). Despite these studies, significant knowledge gaps still exist

Published by Copernicus Publications on behalf of the European Geosciences Union. 
around how much of Australia's historical climate variability can be attributed to SAM and also the role SAM may play in determining Australia's future climate (Kiem and Verdon-Kidd, 2011). Improved characterisation of the role of SAM on Australia's hydroclimate will not only increase our understanding of historical hydroclimate variability, but will also provide valuable performance indicators for global and regional climate models. Realistic climate model representation of SAM and its impacts are crucial given the suggested links between SAM and Australian droughts and the possibility of enhanced SAM impacts in an anthropogenically warmed world. This paper aims to provide a fundamental first step in addressing the knowledge gaps identified above by reviewing the various SAM definitions and indices and analysing the similarities and discrepancies, along with the strengths and weaknesses of each index development approach. Further, the sensitivity of the relationship between SAM and Australian rainfall on choice of SAM index is quantified and recommendations are given as to the most appropriate index to use when assessing the impacts of SAM on Australia's hydroclimate.

\section{The large-scale climate phenomena known as the Southern Annular Mode (SAM)}

Past studies have identified a zonally symmetric or annular structure of circulation in both the Northern and Southern Hemispheres (Rogers and van Loon, 1982; Limpasuvan and Hartmann, 1999; Thompson and Wallace, 2000). This Southern Hemisphere annular structure has been referred to as the Southern Hemisphere Annular Mode (Thompson and Wallace, 1998), Southern Hemisphere Circulation (Karoly et al., 1996), Antarctic Oscillation (Gong and Wang, 1998), High Latitude Mode (Kidson and Watterson, 1999; Simmonds and Keay, 2000; Goodwin et al., 2004) and the Southern Annular Mode (Jones and Widmann, 2004; Gillett et al., 2006; Meneghini et al., 2007). For consistency, the term Southern Annular Mode (SAM) will be used in this paper. SAM is defined as the alternating pattern of strengthening and weakening westerly winds in conjunction with high to low pressure bands between the mid to high latitudes (i.e. polewards of $40^{\circ} \mathrm{S}$ ) in the Southern Hemisphere (Rogers and van Loon, 1982). The alternating, near zonallysymmetric structure is centred at approximately $50^{\circ} \mathrm{S}$. SAM also varies seasonally with a strong zonally symmetric pattern in summer that deteriorates and becomes weaker in winter and spring (J. M. Jones et al., 2009; Kidston et al., 2009).

The fundamental mechanism driving SAM circulation is the non-uniform heating of the Earth and the subsequent energy transport and atmospheric circulations that occur (King and Turner, 2007). The build up of heat and energy near the Equator results in surface convergence and rising air along the Inter-Tropical Convergence Zone (Sturman and Tapper, 2006). The rising air then moves polewards, loses heat and sinks. In the Southern Hemisphere, the subsiding air forms sub-tropical high pressure regions at the surface (around 30$35^{\circ} \mathrm{S}$ in summer and $20-25^{\circ} \mathrm{S}$ in winter). The air moving north from the South Pole intersects with the air moving south from the subtropical high regions and rises. This results in a circumpolar trough, a region of low pressure surrounding Antarctica at approximately $60-70^{\circ} \mathrm{S}$. The regions of longitudinally alternating bounds of high and low pressure may therefore be crudely explained by the non-uniform heating of the Earth and ensuing air and heat transports.

A positive SAM phase is characterised by anomalously high pressure in the mid-latitudes and anomalously low pressures in the latitudes closer to the South Pole. A positive SAM indicates the occurrence of a strengthening circumpolar vortex and zonal (westerly) winds that circle Antarctica (Marshall, 2003) and are associated with a shift in the storm track towards the South Pole (Kidson and Sinclair, 1995). A negative SAM phase exhibits a reverse of the pressure conditions described above and weakening westerly winds associated with a northward shift in the storm track.

A positive SAM is associated with warming of midlatitude areas such as Tasmania, south-east Australia, Chile, Argentina and the south island of New Zealand (Gillett et al., 2006). The seasonal influences of the SAM on rainfall have been shown to be stronger than ENSO over specific regions of Australia, predominantly western Tasmania and southern regions of Australia (Meneghini et al., 2007). Kiem and Verdon-Kidd (2010) also suggested that during a positive SAM phase the rain bearing systems resulting from La Niña are prevented from moving into the SEA region. However, despite these preliminary insights there is a lack of agreement and understanding relating to the relationship between SAM and hydroclimatic variability in Australia, and other Southern Hemisphere regions. For example:

- Gillett et al. (2006) and Cai and Cowan (2006) found that positive SAM phases were associated with below average winter rainfall in SWWA, however, Meneghini et al. (2007) found that positive SAM was associated with above average summer rainfall in SWWA.

- Cai and Cowan (2006) concluded that the robust relationship between SAM and winter rainfall in SWWA explained $67 \%$ of the long-term decline, despite this trend being statistically insignificant. However, Meneghini et al. (2007) deduced that the cause of long term reductions in winter rainfall in SWWA (from 1965 onwards) was unlikely to be due to trends in SAM. Additionally, Feng et al. (2010) later questioned the existence of a relationship between SAM and SWWA winter rainfall, showing that the relationship was only significant when an extreme wet year coupled with an extreme negative SAM value in 1964 is included.

- In contrast to the findings of Gillett et al. (2006) where, apart from Australia, no significant SAM effects were 
Table 1. Summary of SAM index development methods and periods of availability.

\begin{tabular}{|c|c|c|c|c|c|c|c|c|c|}
\hline & & NOAA & jisaoAAO & jisaoSLP & Marshall & SAMI & Visbeck & Fogt & JW58 \\
\hline Method & $\begin{array}{l}\mathrm{PC} \text { reanalysis } \\
\text { Gong and Wang }\end{array}$ & $\sqrt{ }$ & $\sqrt{ }$ & $\sqrt{ }$ & $\sqrt{ }$ & $\sqrt{ }$ & $\sqrt{ }$ & $\sqrt{ }$ & $\sqrt{ }$ \\
\hline Source & $\begin{array}{l}\text { Station readings } \\
\text { Gridded data }^{\mathrm{a}}\end{array}$ & $\sqrt{ }$ & $\sqrt{ }$ & $\sqrt{ }$ & $\sqrt{ }$ & $\sqrt{ }$ & $\sqrt{ }$ & $\sqrt{ }$ & $\sqrt{ }$ \\
\hline Variable & $\begin{array}{l}\text { Sea level pressure } \\
700 \mathrm{hPa} \mathrm{GpH} \\
850 \mathrm{hPa} \mathrm{GpH}\end{array}$ & $\sqrt{ }$ & $\sqrt{ }$ & $\sqrt{ }$ & $\sqrt{ }$ & $\sqrt{ }$ & $\sqrt{ }$ & $\sqrt{ }$ & $\sqrt{ }$ \\
\hline Period & $\begin{array}{l}\text { Start year } \\
\text { End Year }\end{array}$ & $\begin{array}{l}1979 \\
2011^{\mathrm{c}}\end{array}$ & $\begin{array}{l}1948 \\
2002\end{array}$ & $\begin{array}{l}1948 \\
2011^{\mathrm{c}}\end{array}$ & $\begin{array}{l}1957 \\
2011^{\mathrm{c}}\end{array}$ & $\begin{array}{l}1948 \\
2011^{\mathrm{c}}\end{array}$ & $\begin{array}{l}1887 \\
2005\end{array}$ & $\begin{array}{l}1865^{\mathrm{b}} \\
2005\end{array}$ & $\begin{array}{l}1958 \\
2005\end{array}$ \\
\hline Time scale & $\begin{array}{l}\text { Monthly } \\
\text { Seasonal }\end{array}$ & $\sqrt{ }$ & $\sqrt{ }$ & $\sqrt{ }$ & $\sqrt{ }$ & $\sqrt{ }$ & $\sqrt{ }$ & $\sqrt{ }$ & $\sqrt{ }$ \\
\hline
\end{tabular}

a NCEP-NCAR gridded data except for JW58, where ERA-40 data is used. ${ }^{\mathrm{b}} 1865$ for summer and autumn; 1905 for winter and spring. ${ }^{\mathrm{c}}$ Updated monthly.

observed in the Southern Hemisphere north of latitude $40^{\circ} \mathrm{S}$, the studies by Nan and $\mathrm{Li}(2003)$ and Fan and Wang (2004) attributed variations in precipitation and dust events within China to SAM.

The large degree of inconsistency in the findings of existing studies may be due to the limited availability of reliable data in and around the Southern Ocean with which to develop a robust SAM index, resulting in SAM being approximated by numerous indices (discussed in Sect. 3.1). Compounding this is the fact that numerous methods also exist by which to classify SAM into its positive, negative and neutral phases. Kiem and Franks (2001) have previously demonstrated the implications of the subjectivity associated with selecting an index and classification method to characterise impacts associated with large-scale climate drivers. This study builds on that work by investigating the sensitivities associated with the index chosen to represent SAM and the time periods investigated.

\section{Data}

\subsection{SAM indices}

Recent studies aimed at investigating the impacts of the SAM (e.g. Nan and Li, 2003; Reason and Rouault, 2005; Gillett et al., 2006) have resulted in numerous indices being developed to approximate the SAM. These indices differ in either the climate variables used, the data sources used, the method used to define the index, or the time period over which they are determined. The two most common methods by which SAM indices are formulated are:

- Principal Component (PC) analysis: the first PC of a Southern Hemisphere extratropical climate variable (e.g. geopotential height $(\mathrm{GpH})$, mean sea level pressure (MSLP), temperature) (e.g. Thompson and Wallace, 2000; Nan and Li, 2003);

- Gong and Wang (1999) method: the difference between normalised zonal mean pressure between $40^{\circ} \mathrm{S}$ and $65^{\circ} \mathrm{S}$ as shown in Eq. (1).

Gong \& Wang $=P_{40^{\circ} \mathrm{S}}^{*}-P_{65^{\circ} \mathrm{S}}^{*}$

where: $P^{*}$ is the normalized zonal MSLP (at $40^{\circ} \mathrm{S}$ and $65^{\circ} \mathrm{S}$ ) for every month.

Several existing SAM indices that are readily available, commonly used and compared in this study are reviewed below and summarised in Table 1, which shows the method used to construct the index, the data used (source and variable), period of availability and the temporal resolution.

\subsubsection{National Oceanic and Atmospheric Administration (NOAA) index}

Thompson and Wallace (2000) used seven different gridded data sets for variables such as monthly temperature, MSLP, $\mathrm{GpH}$, wind and total column ozone to spatially analyse month to month variability of atmospheric circulations in the polar regions. It was shown that the spatial structure of what is now known as SAM could be identified through the analysis of $\mathrm{GpH}$ anomalies regressed upon their leading principal component time series. Based on the study by Thompson and Wallace (2000), the National Oceanic and Atmospheric Administration (NOAA) calculated (using the PC method) the NOAA index of SAM (referred to by NOAA as Antarctic Oscillation) which is defined as the monthly anomalies of $700 \mathrm{hPa} \mathrm{GpH}$ south of $20^{\circ} \mathrm{S}$ projected onto the first empirical orthogonal function mode of monthly $700 \mathrm{hPa} \mathrm{GpH}$ during 1979-2000. The NOAA SAM index is based on data 
derived from a numerical weather prediction model that assimilates both station observations and satellite data. Satellite data has enabled large quantities of wide-spread observations in the Antarctic region since the late 1970s (King and Turner, 2007). It follows that gridded data that incorporates satellite data is less influenced by spurious errors encountered with earlier reanalysis data (Marshall, 2003). Hence the NOAA index, which is available from 1979 onwards and incorporates the use of satellite data, will be used as the baseline, or reference index, for the remainder of this study. The NOAA index data is updated in real time and can be accessed at: http://www.cpc.ncep.noaa.gov/products/precip/ CWlink/daily_ao_index/aao/aao.shtml.

\subsection{2 jisaoAAO index and jisaoSLP index}

Fan and Wang (2004) calculated a SAM index, referred to here as the Joint Institute for the Study of Atmosphere and Ocean (jisao) Antarctic Oscillation Index (AAO). The definition of jisaoAAO is based on the first $\mathrm{PC}$ of $850 \mathrm{hPa} \mathrm{GpH}$ anomalies south of $20^{\circ} \mathrm{S}$. This SAM index is calculated using National Centres for Environmental Prediction-National Centre for Atmospheric Research (NCEP-NCAR) data from 1954 to 2002. Since release of the Fan and Wang (2004) study, the jisaoAAO record has been extended to 1948 (still ending in 2002) and is available on: http://jisao.washington. edu/data/aao/.

Fan and Wang (2004) compiled another index, referred to in this paper as jisaoSLP, in order to assess the occurrences of dust in storms in northern China, which are particularly prevalent during the boreal spring (consisting of the months March, April and May (MAM)). The jisaoSLP is calculated using the first PC of MSLP anomalies south of $20^{\circ} \mathrm{S}$ averaged over the boreal winter (or austral summer consisting of the months of December, January and February (DJF)) and spring months (MAM) with the data set beginning in 1954. This data set has now been extended back to 1948 and is regularly updated and available at: http://jisao.washington.edu/data/aao/slp.

\subsubsection{Regional Antarctic Oscillation Index (AOIR)}

Meneghini et al. (2007) used the Gong and Wang (1999) definition of the SAM, however, their analysis concerned seasonal rainfall and as such, the index was redefined to provide a seasonal SAM index:

$$
\begin{aligned}
\operatorname{AOIR}(t) & =\frac{\operatorname{MSLP}_{40^{\circ} \mathrm{S}}(t)-\overline{\mathrm{MSLP}_{40} \mathrm{~S}}(\text { season })}{\sigma_{\mathrm{MSLP}} 40^{\circ} \mathrm{S}(\text { season })} \\
& -\frac{\mathrm{MSLP}_{65^{\circ} \mathrm{S}}(t)-\overline{\mathrm{MSLP}_{65^{\circ} \mathrm{S}}(\text { season })}}{\sigma_{\mathrm{MSLP}} 65^{\circ} \mathrm{S}(\text { season })}
\end{aligned}
$$

where: MSLP (t) is the seasonal MSLP; $\overline{\operatorname{MSLP}(\text { season })}$ is the mean of the seasonal MSLP for the season of interest; and $\sigma$ (season) is the standard deviation of the seasonal MSLP for the season of interest.

This seasonal SAM index was calculated using the European Centre for Medium Range Weather Forecasts' Reanalysis (ERA) ERA-40 gridded monthly MSLP data set and resulted in one AOI value per season per year. The AOIR used only data between $90^{\circ} \mathrm{E}$ to $180^{\circ} \mathrm{E}$ to encompass all of Australia and make it region specific. Although this data set is no longer available, and therefore is not assessed in this study, the methodology used to develop a region specific index for quantifying SAM proved to be useful in identifying SAM effects on Australian rainfall.

\subsubsection{Marshall index}

Marshall (2003) also used the Gong and Wang (1999) definition to develop an index of SAM. However, the Marshall (2003) index was based on station data (as opposed to reanalysis data), which measured the monthly mean difference between the MSLP at six stations close to $40^{\circ} \mathrm{S}$ and six stations close to $65^{\circ} \mathrm{S}$. Variations in Southern Hemispheric temperature (Marshall, 2007) and precipitation (Silvestri and Vera, 2009; Feng et al., 2010) have been attributed to SAM behaviour through the use of the Marshall index. The index is available from 1957 to the present and is available at: http://www.antarctica.ac.uk/met/gjma/sam.html.

\subsubsection{Southern Annular Mode Index (SAMI)}

Nan and Li (2003) created the Southern Annular Mode Index (SAMI) for the period of 1948-2001 based on the Gong and Wang (1999) method but with the difference being that SAMI is defined as the difference between the normalized monthly zonal MSLP between $40^{\circ} \mathrm{S}$ and $70^{\circ} \mathrm{S}$ (as opposed to $40^{\circ} \mathrm{S}$ and $65^{\circ} \mathrm{S}$ ). Nan and $\mathrm{Li}(2003)$ believed that the negative correlation in the zonal MSLP anomalies between $40^{\circ} \mathrm{S}$ and $70^{\circ} \mathrm{S}$ was stronger than between $40^{\circ} \mathrm{S}$ and $65^{\circ} \mathrm{S}$. Although Thompson and Wallace (2000) show that this is not the case, the SAMI was formulated to be region specific as spring SAMI showed stronger correlations with summer rainfall in the Yangtze River valley. SAMI has since been updated to the present and is available on: http://web.lasg.ac. $\mathrm{cn} /$ staff/ljp/data-NAM-SAM-NAO/SAM-AAO.htm.

\subsubsection{Visbeck index}

Visbeck (2009) developed an index of SAM using a similar method to Marshall (2003). However, the Visbeck index used different selection criteria for stations, resulting in the inclusion of 43 stations to develop the index. This index begins in 1958, as this is when improved data coverage for Antarctic stations became available. The Visbeck index was then extended through a method of reconstructing the Antarctic MSLP time series (Visbeck, 2009) based on the concept of atmospheric mass conservation between Antarctica and subtropical latitudes. The reconstructed Visbeck SAM index 
was originally extended to 1884 , however, since publication, a stricter revision of the station selection criteria resulted in the reconstruction being shortened and data only being available from 1887 (M. Visbeck, personal communication, 2010). The Visbeck index is formulated in three monthly periods from the start of the calendar year (JFM, AMJ, JAS, OND) and is available through: http://www.ifm-geomar.de/ fileadmin/ifm-geomar/fuer_alle/PO/SAM/sam_annual.tab. A monthly data set is also available and was obtained through personal communication with M. Visbeck (personal communication, 2011).

\subsubsection{Fogt index and the Jones and Widmann index}

Relationships developed from the ERA-40 reanalysis MSLP data from 1958-2001 and station MSLP data were used to produce the SAM index prior to 1958 for both the Fogt reconstructed index and the Jones and Widmann (JW) reconstructed indices. PC analysis, as described in Sect. 2.1, was used to calculate both indices (J. M. Jones et al., 2009). The key difference in the reconstructions was that the Fogt reconstructions were fitted to the Marshall index, whilst the JW reconstructions were fitted to a SAM index using ERA-40 data (1958-2001) and the PC method of developing a SAM index. The Fogt reconstructions are available through: http: //polarmet.osu.edu/acd/sam/sam_recon.html. The JW reconstructions were obtained through personal communication from 1866 to 2005. Several JW reconstructions were developed with different starting dates of 1866, 1905, 1951 and 1958. Of the JW reconstructions, only the index with the start date of 1958 (JW58 index) is used in this study, as this JW reconstruction uses the most stations in reconstructing the SAM index for the post 1979 analysis period and has also been shown to be a better indicator of SAM than the longer JW reconstructions (J. M. Jones et al., 2009).

According to J. M. Jones et al. (2009) both the Fogt and JW58 reconstructions are most robust during the austral summer (DJF) due to the nature of the SAM being most zonally symmetric during this season. As the SAM's zonal symmetry begins to break down after summer, spring proved to be the most problematic season for SAM reconstructions, followed by winter and autumn, where a reduced number of stations could be utilised to reconstruct the index (J. M. Jones et al., 2009). Fogt reconstructions proved to be more reliable than the JW reconstructions during JJA and SON while both Fogt and JW reconstructions were deemed to be equally reliable in DJF and MAM (J. M. Jones et al., 2009).

\subsection{Rainfall data}

The Australian Monthly Gridded Rainfall Data set (19002008) from the Australian Bureau of Meteorology is used to compare the relationship between Australian surface rainfall and the various SAM indices (http://www.bom.gov.au/ climate/how/newproducts/IDCmrgrids.shtml, D. A. Jones et al., 2009). The gridded data has been generated from observed data using an optimized Barnes successive correction technique (Barnes, 1973) that applies a weighted averaging process to the station data.

\section{Method}

This analysis compares SAM indices and the sensitivity associated with choice of SAM index when seeking to quantify the relationship between Australian rainfall and SAM. SAM indices were compared on seasonal and, where possible, monthly resolutions. As the NOAA index is only available from 1979 onwards and the jisaoAAO is only complete to 2002, all indices were compared over the same period (1979 to 2002) via correlations and scatter plots. The scatter plots were all developed using the NOAA index as the point of reference (for reasons discussed in Sect. 3.1.1). All indices were normalised on a seasonal, and where available a monthly, scale by subtracting the seasonal/monthly mean (calculated over the 1979 to 2002 period) and dividing by the seasonal/monthly standard deviation to enable all scatter plots to be easily comparable.

As the suite of SAM indices are calculated from three different data sets (i.e. station data, NCEP-NCAR reanalysis data and ERA-40 reanalysis data) one potential source of difference between the indices is the source data used to calculate each index (with the other potential source of difference being the method used to calculate or define each index). In order to assess whether source data is important or whether differences between SAM indices are just due to the different SAM index definitions, the Marshall and Visbeck indices were recalculated using both NCEP-NCAR and ERA-40 data. The two station data based indices were chosen for this assessment as a recalculation of the gridded data based indices using station data would be complicated by the availability and quality of station data in the higher latitudes. Further, if differences are seen in the station based indices when they are recalculated using gridded data then it is logical to infer that similar differences would be seen in the gridded data based indices if they were recalculated using station data (i.e. SAM indices are sensitive to the source data used to calculate them).

Next, to quantify the sensitivity associated with choice of SAM index when seeking to quantify relationships between Australian rainfall correlations were calculated, for each season, between the different SAM indices and Australian rainfall for the period over which all of the SAM indices being investigated are available (i.e. 1979-2002). This enables equitable comparisons to be made.

The temporal variability of SAM impacts on Australian rainfall is also demonstrated via seasonal correlations between the Visbeck SAM index (chosen because of its length of availability (refer to Table 1) and Australian rainfall over 
Table 2. Correlation between various SAM indices at a seasonal resolution (normalised for the period where all indices are available: 1979-2002).

\begin{tabular}{lllllllll}
\hline & NOAA & jisaoAAO & jisaoSLP & Marshall & SAMI & Visbeck & Fogt & JW58 \\
\hline NOAA & 1 & 0.981 & 0.968 & 0.903 & 0.945 & 0.890 & 0.670 & 0.712 \\
jisaoAAO & & 1 & 0.989 & 0.893 & 0.955 & 0.897 & 0.650 & 0.704 \\
jisaoSLP & & & 1 & 0.895 & 0.961 & 0.911 & 0.643 & 0.695 \\
Marshall & & & & 1 & 0.880 & 0.880 & 0.700 & 0.695 \\
SAMI & & & & & 1 & 0.874 & 0.686 & 0.677 \\
Visbeck & & & & & 1 & 0.642 & 0.670 \\
Fogt & & & & & & & 0.784 \\
JW58 & & & & & & & & \\
\hline
\end{tabular}

1979-2002 (the "baseline") and 1900-2005 (the period of where both rainfall and Visbeck data are available).

\section{Results}

\subsection{Comparison of seasonal and monthly SAM index values}

Table 2 shows the correlations between the NOAA index and the remaining indices on a seasonal scale over the period where all index data is available (i.e. 1979-2002). All correlations are statistically significant at the 99th percentile.

Both jisao indices and the NOAA index are highly correlated. This result was somewhat expected given that the NOAA, jisaoSLP and jisaoAAO indices are all developed using the PC analysis method and NCEP-NCAR reanalysis pressure data. SAMI is also highly correlated to the NOAA and jisao indices, despite being based on the Gong and Wang (1999) method and this is perhaps because the SAMI also utilises NCEP-NCAR reanalysis pressure data. There is a clear difference between the indices based on gridded reanalysis data and the indices based on station observations (i.e. the Marshall and Visbeck indices). Marshall (2003) has previously shown that the use of NCEP-NCAR data exaggerates trends in the SAM signal by a factor of two or three, especially in winter, due to the nature of the NCEP-NCAR reanalysis, which has a positive pressure bias at higher latitudes compared with station data that decreases through time. Of the indices available prior to 1950 (i.e. Fogt, JW58, Visbeck), Visbeck is the most highly correlated with the NOAA index (used as the reference point in this study as it utilises gridded data that is based on a mixture of satellite data and observed surface data). The notable difference between the Visbeck index and both the Fogt and JW58 indices is that the Visbeck index uses a method of reconstructing sea level pressures in the mid-latitudes in order to gain insights into SAM behaviour and hence create a physically based extended SAM index record prior to the availability of continuous station records. In contrast to the physically based Visbeck method, the Fogt and JW reconstructions (note that as previously discussed in Sect. 3.1.7, JW58 is the only JW index assessed in this paper) were based on statistical regression models developed using long-term station data (starting as far back as 1865) as predictors and relationships between the Marshall index (for Fogt) and ERA-40 MSLP PC (for JW).

To further investigate the similarities and differences between the various SAM indices in comparison to the NOAA index, scatter plots of the normalised SAM index values against the normalised NOAA index were developed. Figure 1 shows the seasonal index values plotted against the corresponding seasonal NOAA index value for the same time period (1979-2002). Many hydroclimatic studies are however focused on sub-seasonal timescales, where monthly and weekly information on climate states are required for historical investigations as well as for forecasts. Therefore it is also necessary to compare monthly SAM indices and, for the SAM indices that are available at a monthly resolution (see Table 1), this is shown in Fig. 2.

For both Figs. 1 and 2 consistency between indices (i.e. the NOAA index and the SAM index being compared) is depicted by a clustering of data points around the 1:1 gradient and, importantly, no data points in the second and fourth quadrants. Data points in the second and fourth quadrants indicate a complete disagreement from the indices as to what the SAM phase is for a given season (i.e. one index is suggesting positive SAM conditions while the other is indicating negative SAM). This is of concern as it indicates the choice of index may result in the phase of SAM being incorrectly identified which could lead to misrepresentation of SAM's influence and incorrect attribution of hydroclimatic variability to SAM behaviour.

Figure 1 shows similar patterns to Table 2, in that all indices correlate well with NOAA except Fogt and JW58 and, to a lesser degree, Visbeck. In particular, the jisaoAAO and jisaoSLP show little variation in comparison to the NOAA index, however, there is an increasing degree of scatter for the Marshall, SAMI and Visbeck indices. It also appears that the NOAA index is often greater in magnitude than either the Marshall or Visbeck indices. Figure 1f (Fogt against NOAA) 


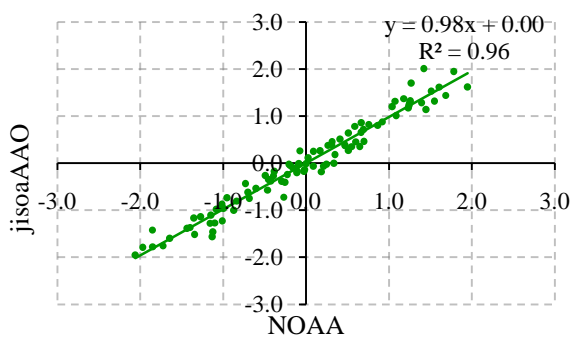

(a)

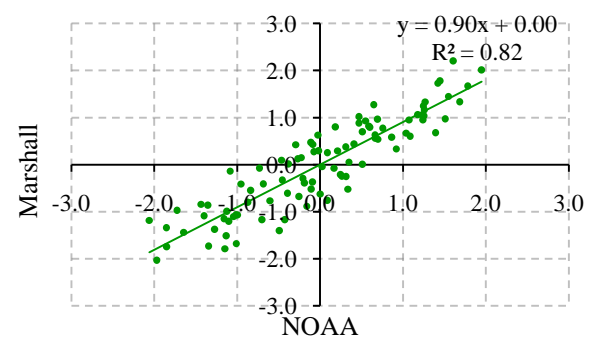

(c)

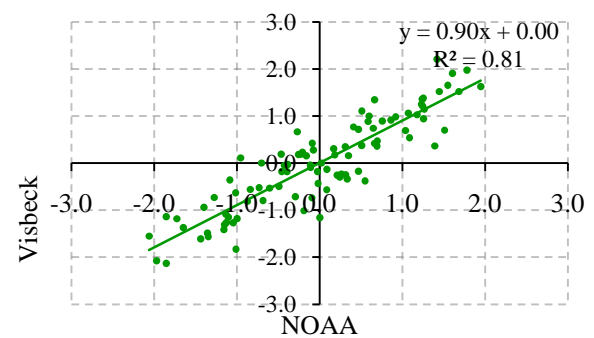

(e)

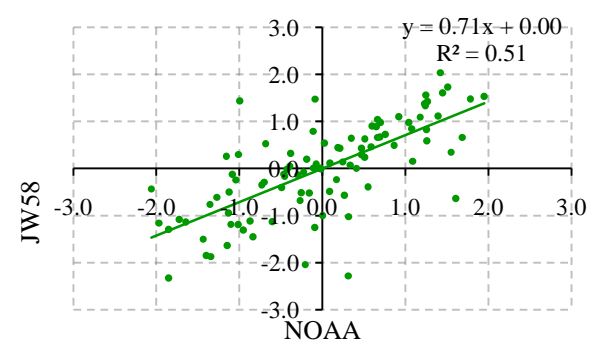

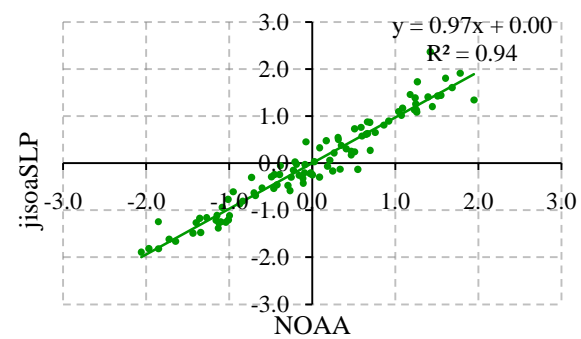

(b)

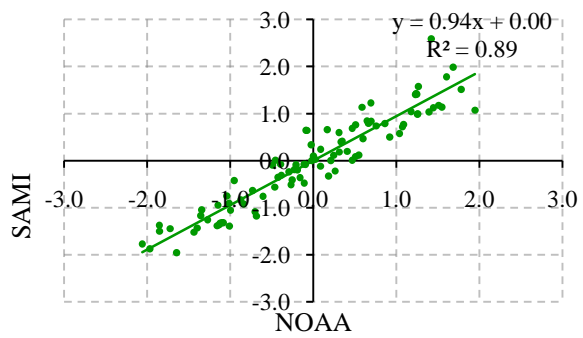

(d)

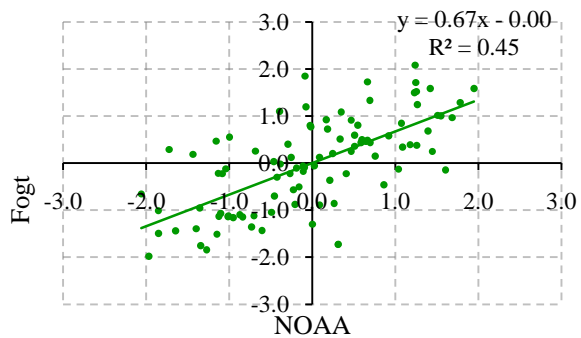

(f)

(g)

Fig. 1. Seasonal SAM index values plotted against seasonal NOAA index (normalised 1979-2002) for (a) jisaoAAO; (b) jisaoSLP; (c) Marshall; (d) SAMI; (e) Visbeck; (f) Fogt and (g) JW58.

and Fig. 1g (JW58 against NOAA) show an increased number of data points recorded in the second and fourth quadrants, indicating a high degree of inconsistency with the NOAA index. The results are replicated at the monthly resolution (Fig. 2) suggesting that a SAM index that is acceptable at the seasonal scale will behave in a similar fashion at the monthly scale.

The results from Figs. 1 and 2 indicate that if you were to characterise the relationship between SAM and hydroclimatic variability at a given location then you could expect similar results if you used the NOAA, jisaoAAO, jisaoSLP SAM indices, slightly different results if you used Marshall, SAMI or Visbeck, and extremely different results if you used Fogt or JW58 (indeed in some cases the results obtained using Fogt and JW58 would be the direct opposite to those obtained using any of the other indices). This highlights the importance of acknowledging the subjectivity, and quantifying the uncertainty, associated with choice of climate index (e.g. Kiem and Franks, 2001; Verdon and Franks, 2005). 


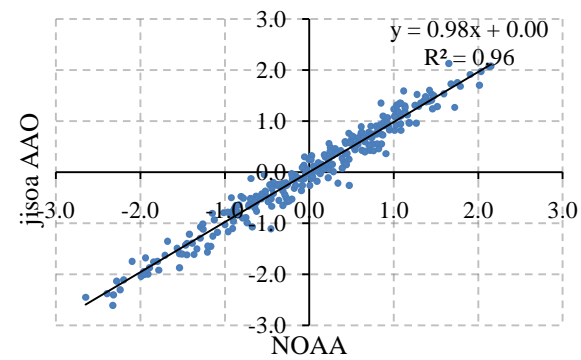

(a)

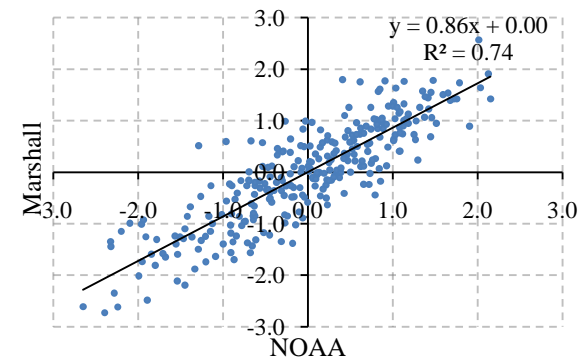

(c)

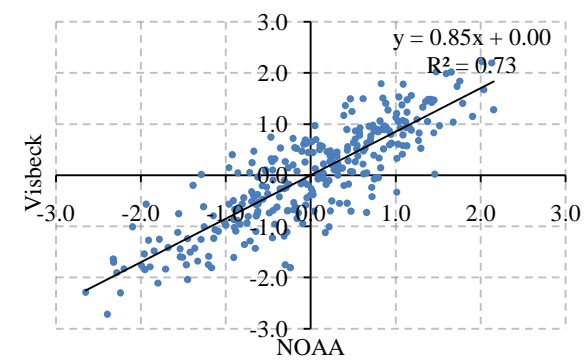

(e)

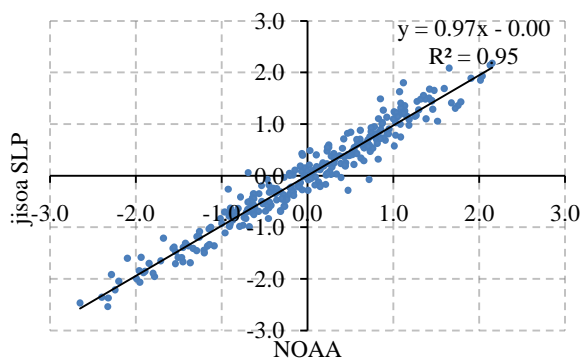

(b)

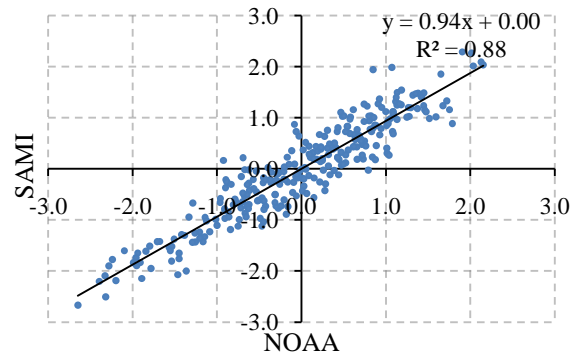

(d)

Fig. 2. Monthly SAM index values plotted against monthly NOAA index (normalised 1979-2002) for (a) jisaoAAO; (b) jisaoSLP; (c) Marshall; (d) SAMI; (e) Visbeck; (f) Fogt and (g) JW58.

\subsection{Assessing the impact of using different data sets to calculate SAM indices}

SAM indices differ through both the method used to generate (or define) the index and the source data used to calculate the index. To determine how much of the disparity between the various SAM indices (Sect. 5.1) can be attributed to differing source data, the Marshall and Visbeck indices were recalculated using both NCEP-NCAR and ERA-40 MSLP reanalysis data. The Marshall and Visbeck SAM index definition and calculation methods were kept exactly the same with the only difference being that the station data used to calculate the indices was replaced with information from relevant NCEP-NCAR and ERA-40 reanalysis grids (i.e. from the grids within which each station was located). Figure $3 \mathrm{a}$ compares the original station based SAM indices with reanalysis data based equivalents while Fig. $3 \mathrm{~b}$ compares just the reanalysis versions of Marshall and Visbeck.

Figure $3 \mathrm{a}$ and b show that $R^{2}$ values obtained when comparing the station based and reanalysis gridded data based versions of both the Marshall and Visbeck SAM indices range from 0.60 to 0.85 , suggesting that some of the disparity between SAM indices seen in Figs. 1 and 2 is indeed due to the source data sets used to calculate them. Further, there is no consistency as to which reanalysis data set aligns more closely with the station based version of the Marshall and Visbeck indices with NCEP-NCAR matching the station based Marshall more closely and the ERA-40 providing a closer match to the station based Visbeck. These results clearly demonstrate that even if there was one accepted SAM definition and method of index calculation at least some of the differences, and implications associated with those differences, discussed in Sect. 5.1 will remain unless a single source data set is also agreed upon.

\subsection{Seasonal relationships between various SAM indices and Australian rainfall}

In order to assess the inconsistencies resulting from the subjectivity associated with choice of SAM index, an 


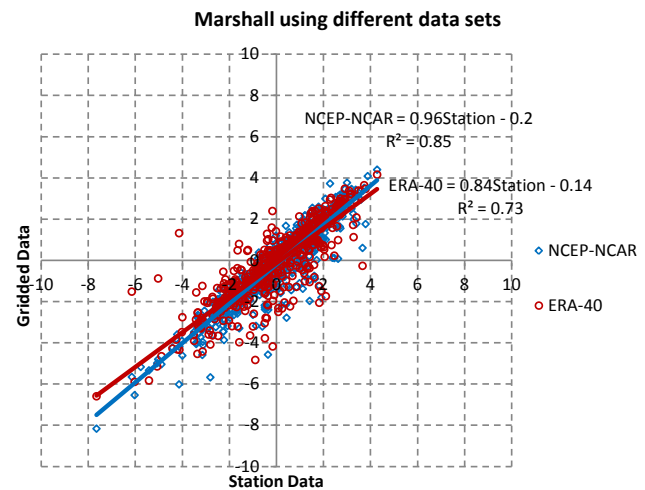

a i)

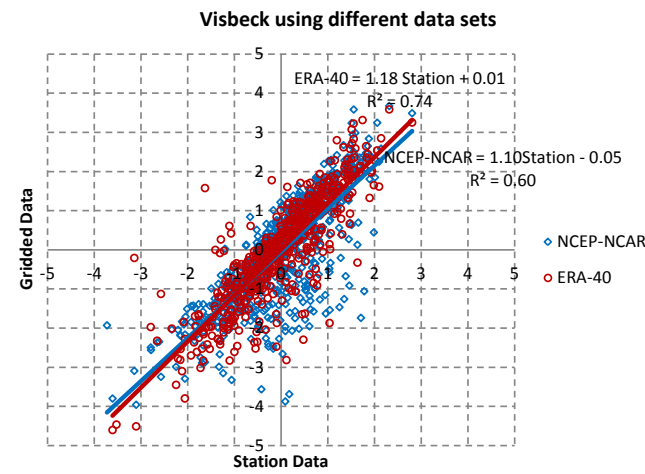

a ii)

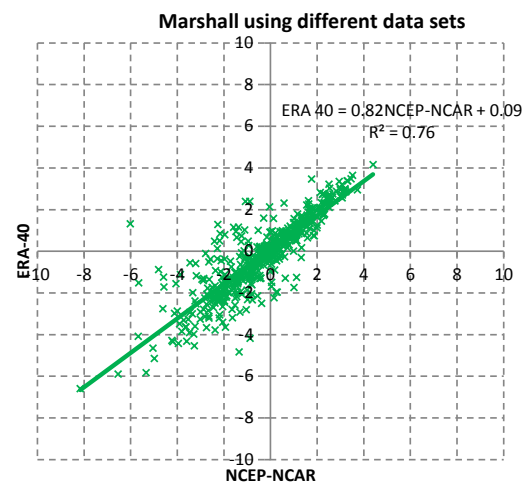

b i)

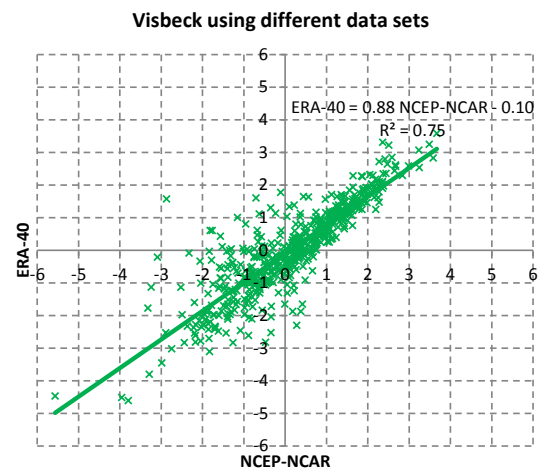

b ii)

Fig. 3. (a) Station based monthly (i) Marshall and (ii) Visbeck SAM indices compared with their NCEP-NCAR and ERA-40 equivalents and (b) comparison between monthly (i) Marshall and (ii) Visbeck SAM indices recalculated using NCEP-NCAR and ERA-40 reanalysis data.

investigation into the differences in the correlations between Australian rainfall and SAM, as represented by the various SAM indices, was undertaken. It is important to note that correlations are only used in this study to identify the differences between the SAM indices (i.e. in a comparative study), not to establish relationships between SAM and Australian rainfall. The limitations associated with using correlations in establishing hydroclimatic relationships are discussed in Sect. 6.

SAM is a climate mechanism that has varying seasonal impacts. It is therefore necessary to consider the correlations between seasonal SAM indices and seasonal rainfall and the results for this are presented in the following sections. Note that the analysis is conducted over a consistent period, 19792002 where all SAM indices are available, to enable comparison of the relationship of various SAM indices and Australian rainfall with the uncertainties associated with length of SAM index availability removed. Also, for each season and SAM index only statistically significant correlations are shown (i.e. Pearson correlation with absolute value greater than 0.3882 which is significant at the 95 th percentile for two tails and 24 data points, one for each year 1979-2002).

\subsubsection{Summer (DJF)}

Figure 4 shows the correlation between summer SAM indices and summer rainfall. Broadly speaking, similar patterns are observed for the NOAA, jisaoAAO and jisaoSLP indices (consistent with Sect. 5.1) and these relationships (which are consistent with the results of Risbey et al., 2009) are totally different to those obtained using Fogt and JW58 indices. The Fogt and JW 58 indices both show negative correlations with SWWA and a reduced spatial extent of positive correlations in central Australia with some negative correlations seen in central-eastern Australia (reasons for this are previously discussed in Sect. 5.1).

\subsubsection{Autumn (MAM)}

As with summer, there are significant similarities and differences observed in the relationship between autumn rainfall and SAM depending on the choice of SAM index (Fig. 5). A negative correlation in SWWA is seen in all of the indices with the exception of the Fogt index. Positive correlations between autumn rainfall and SAM are found for northern Australia (to varying degrees depending on choice/length of SAM index). This is consistent with Meneghini et al. (2007) who found significant correlations in autumn were located 

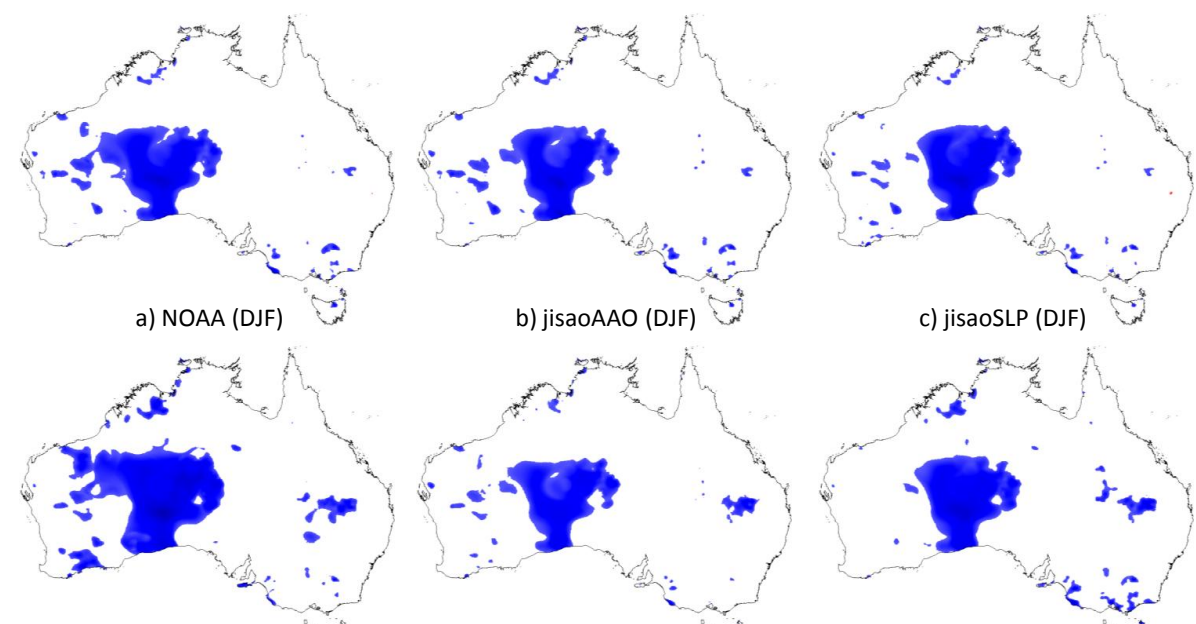

c) jisaoSLP (DJF)

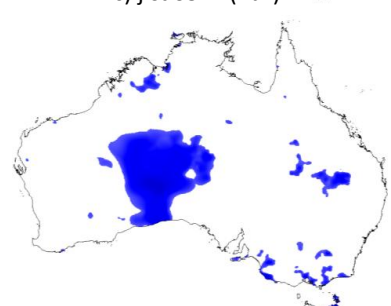

d) Marshall (DJF)

e) SAMI (DJF)
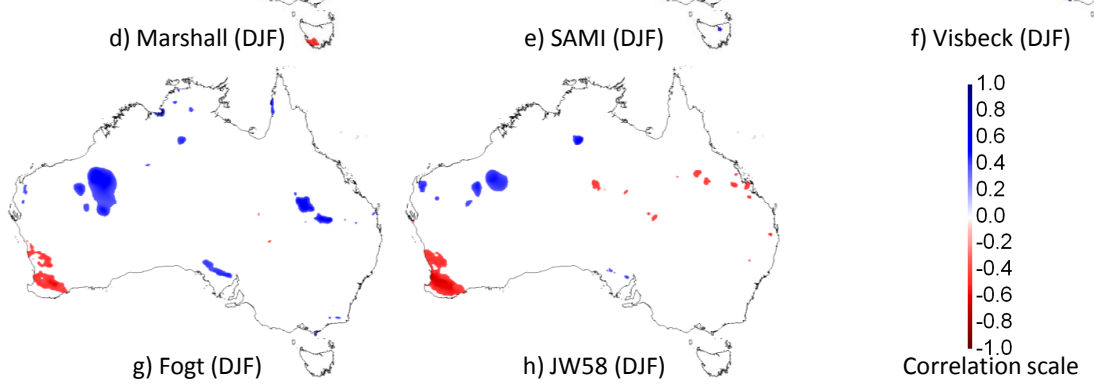

Fig. 4. Correlations between total summer (DJF) rainfall and summer SAM indices, 1979-2002 (a) NOAA; (b) jisaoAAO; (c) jisaoSLP; (d) Marshall; (e) SAMI; (f) Visbeck; (g) Fogt and (h) JW58. Note: only correlations that are statistically significant at the 95th percentile are shown.

in northern and north-west central Australia. However, as with summer, the Fogt and JW58, and also Visbeck, (Fig. 5fh) show a markedly different pattern with reduced positive correlations in northern Australia and for the Fogt index, stronger correlations in western and central Australia (as previously discussed in Sect. 5.1).

\subsubsection{Winter (JJA)}

Figure 6 shows the correlation between winter SAM indices and winter rainfall over the period 1979-2002. Negative correlations between winter rainfall and winter SAM indices (with the exception of the Visbeck and JW58 indices) are a consistent feature for SWWA and SEA, including Tasmania, which supports the work of Risbey et al. (2009). Interestingly, Meneghini et al. (2007) found significant positive correlations between SAM and eastern Australia rainfall during winter, however similar results are only indicated here when the jisaoSLP, SAMI, Visbeck or JW58 index is used (Fig. 6c, $\mathrm{e}, \mathrm{f}$, and $\mathrm{h}$ ) whereas a weaker correlation (or in some cases no correlation) is seen when the remaining indices are analysed. This again highlights the fact that completely different insights can be obtained depending on which SAM index is analyzed.

\subsubsection{Spring (SON)}

Figure 7 shows the correlation between spring SAM indices and spring rainfall over the period 1979-2002. The dominance of positive correlations between spring SAM and spring rainfall in Australia (excluding western Tasmania, where negative correlations were observed) is consistent with previous work by Hendon et al. (2007) and Risbey et al. (2009), however are inconsistent with the study by Meneghini et al. (2007). Although the correlation patterns between spring rainfall and spring SAM indices appear to be similar for all the indices, there is still variability between the indices with respect to the strength and spatial extent of the correlations.

The results displayed in Fig. 4 through to Fig. 7 are based on data over the period when all SAM index data are available (1979-2002). This analysis was carried out simply to illustrate that different relationships are obtained when various SAM indices are correlated with Australian rainfall over the same time period. This result was somewhat expected, however clearly the issue of choice of index is often overlooked given that SAM indices are used interchangeably and teleconnections obtained using one SAM index are assumed to represent the relationship between SAM and Australian rainfall in the past, now and into the future. 


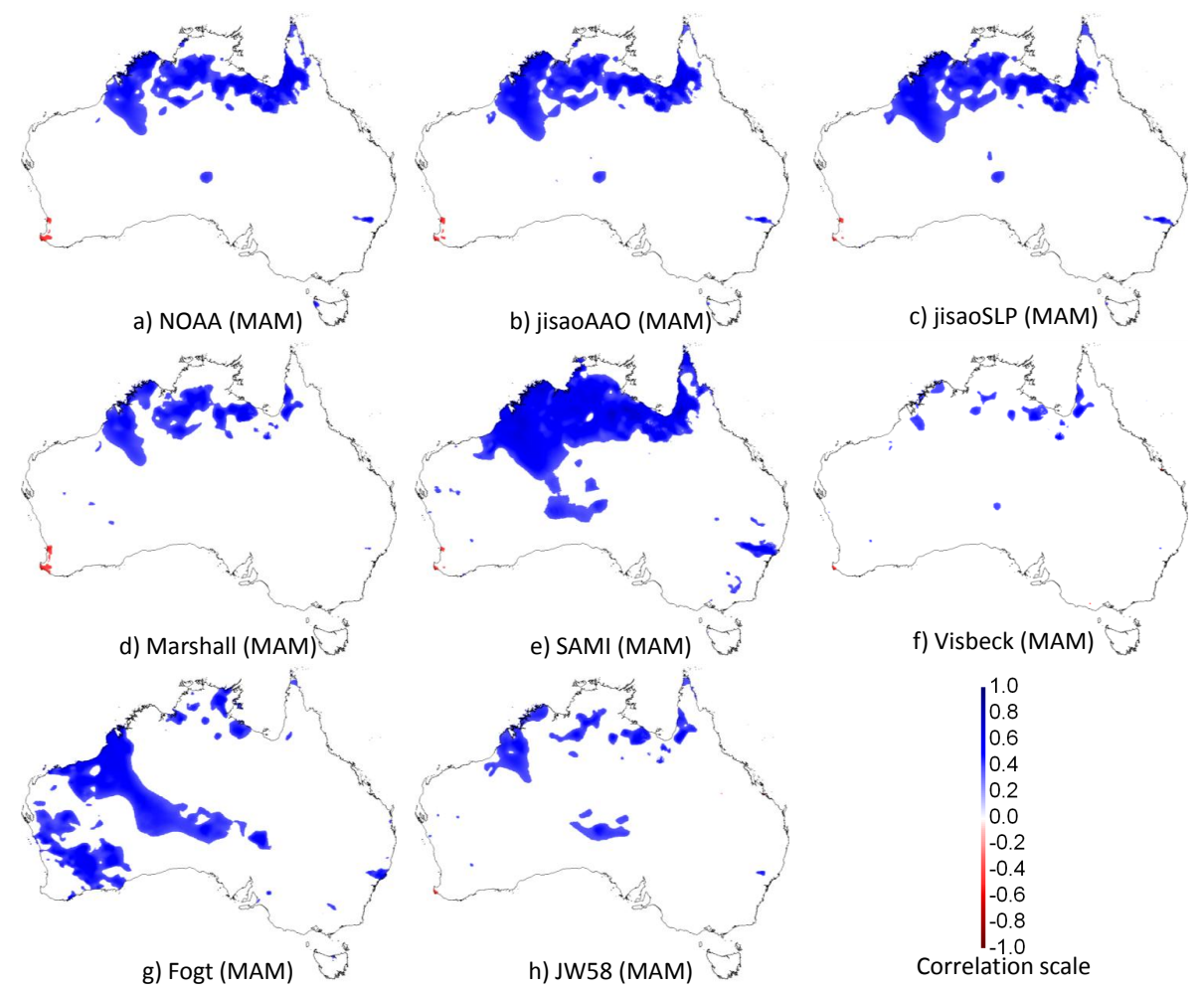

Fig. 5. Correlations between total autumn (MAM) rainfall and autumn SAM indices, 1979-2002 (a) NOAA; (b) jisaoAAO; (c) jisaoSLP; (d) Marshall; (e) SAMI; (f) Visbeck; (g) Fogt and (h) JW58. Note: only correlations that are statistically significant at the 95th percentile are shown.

\subsection{Temporal variability of relationship between SAM and Australian rainfall}

In order to determine if there is temporal variability in the relationship between SAM and Australian rainfall, the seasonal correlations between Australian rainfall and the Visbeck index are illustrated over the periods 1979-2002 (Fig. 8a) and 1900-2005 (Fig. 8b), the period when both rainfall and Visbeck data are available.

In general, across all seasons, differences in the spatial extent of positive or negative correlations are observed between the shorter (1979-2002) and longer (1900-2005) analysis periods, indicating that the role SAM plays in driving Australian rainfall may be temporally variable (i.e. nonstationary). However, other explanations for the differences observed between Fig. 8a and b should also be considered and investigated further, such as improved observations (both rainfall and data used to calculate the Visbeck index) over recent decades and the fact that correlations typically weaken over longer time periods.

Nevertheless, given the differences in correlation coefficients both spatially and seasonally, Fig. 8 confirms that the relationship between SAM and Australian rainfall varies not only depending on the choice of SAM index (both method and data source), but also on the time period of analysis.
Previous studies such as Silvestri and Vera (2009) and Feng et al. (2010) have also observed temporal variability in the impacts of SAM on rainfall in the Southern Hemisphere and it follows that the relationship between SAM and Australian rainfall cannot be assumed to be stationary, a theory supported by the analysis presented in this paper.

It is likely that over longer timescales, other climate drivers may be more dominant over the regions that show opposing correlations when different time periods are considered (such as eastern Australia in summer, SEA in autumn and winter, Western Australia in winter, and north-west Australia in spring). In addition, SAM influences on Australian rainfall are possibly subject to multi-decadal modulation via other climatic drivers. This could be similar to the way the IPO modulates the frequency and magnitude of ENSO impacts in Australia (e.g. Power et al., 1999; Kiem et al., 2003; Kiem and Franks, 2004; Verdon et al., 2004). The potential multi-decadal modulation of the frequency and magnitude of SAM impacts is an area that warrants further investigation due to the important implications for hydroclimatic studies in Australia (including seasonal forecasting, climate attribution studies and long term climate change projections). 


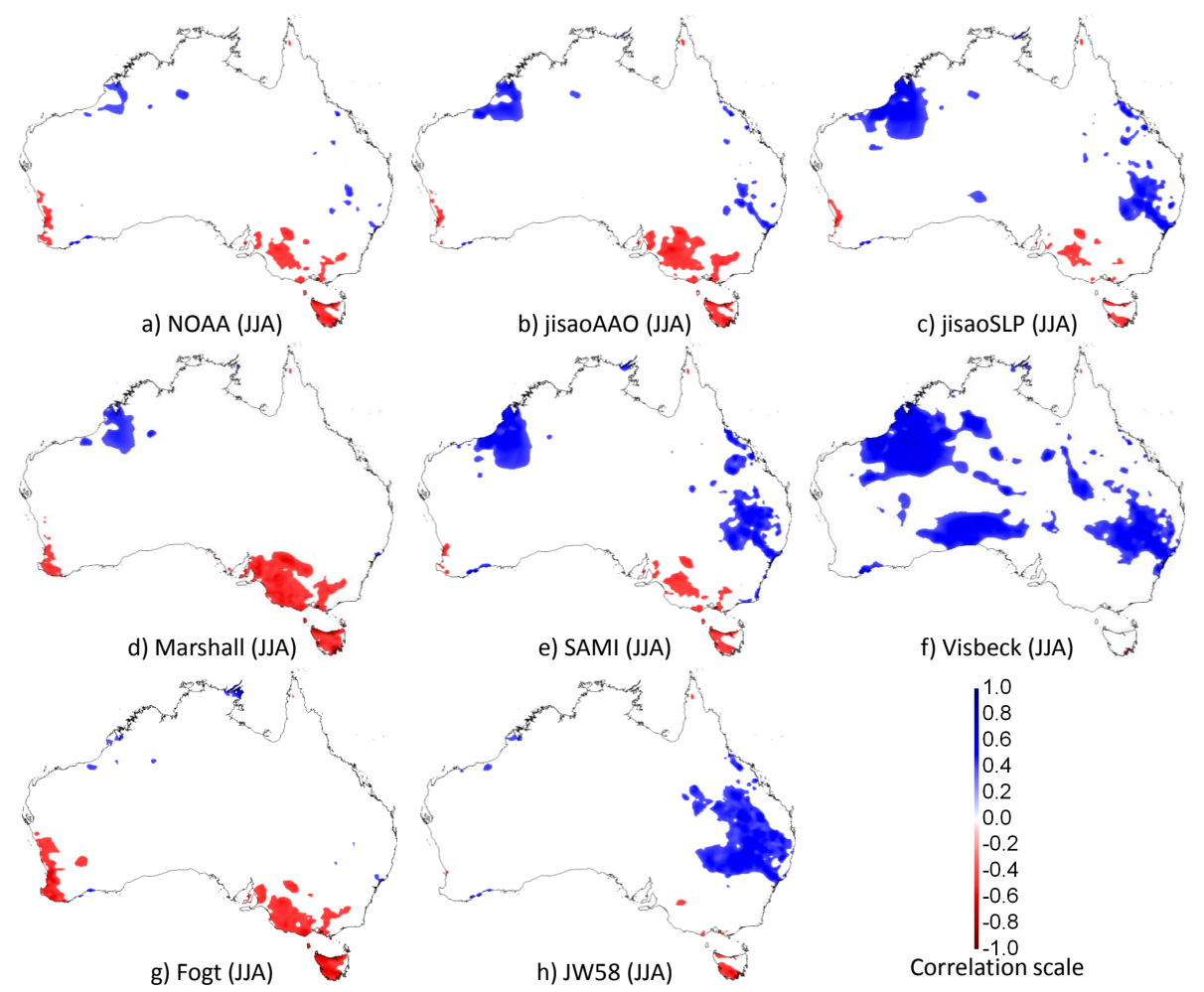

Fig. 6. Correlations between total winter (JJA) rainfall and winter SAM indices, 1979-2002 (a) NOAA; (b) jisaoAAO; (c) jisaoSLP; (d) Marshall; (e) SAMI; (f) Visbeck; (g) Fogt and (h) JW58. Note: only correlations that are statistically significant at the 95th percentile are shown.

\section{Discussion and conclusions}

The results presented here demonstrate that, despite supposedly representing the same physical process, there are differences in the various indices used to represent SAM. These differences are dependent on the method, variable, or source of data used to develop the index. In some cases (e.g. Fogt and JW58) these differences are marked and lead to large uncertainty as to whether the SAM is in its positive or negative phase. Section 5.3 demonstrates the implications of this uncertainty when trying to determine the seasonal relationship between SAM and Australian rainfall. Indeed, the magnitude and spatial pattern of the relationships vary markedly depending on the SAM index chosen and the data set used to calculate that index (Sect. 5.2). Therefore, given the numerous studies that have suggested that SAM is responsible for at least some of Australia's hydroclimatic variability, and the fact that the results and conclusions in these previous studies are not always consistent, the following questions emerge: (a) which index most satisfactorily represents SAM?; (b) what is the true relationship between SAM and Australia's temporal and spatial hydroclimatic variability?; and (c) how is SAM related to, or how does SAM interact with, other large-scale (e.g. ENSO, IOD, IPO) climate drivers and local-scale weather patterns known to influence Australian hydroclimatology?
To answer the first question, numerous studies have shown that the SAM annular structure is best characterised by MSLP, $700 \mathrm{hPa}$ or $850 \mathrm{hPa} \mathrm{GpH}$ measurements, with readings at latitudes $40^{\circ} \mathrm{S}$ and $65^{\circ} \mathrm{S}$ being the most suitable for identifying the nature of SAM (Gong and Wang, 1999). Given this physical basis, it then follows that the NOAA and jisaoAAO could be considered good indicators of SAM behaviour, since they are based on the physical understanding outlined above. As discussed in Sect. 5.1, the jisaoSLP and SAMI are also very similar (Table 2, Figs. 1 and 2) to NOAA and jisaoAAO (over the period 1979-2002) implying that NOAA, jisaoAAO, jisaoSLP or SAMI could be used with equal confidence to represent SAM - noting that NOAA is only available from 1979 (whereas the other three are available from 1948) and jisaoAAO is not available after 2002. A common factor between NOAA, jisaoSLP, jisaoAAO and SAMI is the use of NCEP-NCAR reanalysis data to calculate the respective indices. The advantage of reanalysis data is the availability of information with a broader spatial coverage (as opposed to station based data which is somewhat limited in the Southern Hemisphere). However, Marshall (2003) warns that spurious trends exist in the reanalysis data and that the strengthening SAM signal observed over past decades is magnified by a factor of two to three in the NCEP-NCAR reanalysis data. Also, seasonal analysis using NCEP-NCAR data incorrectly identifies the greatest increasing SAM trends 

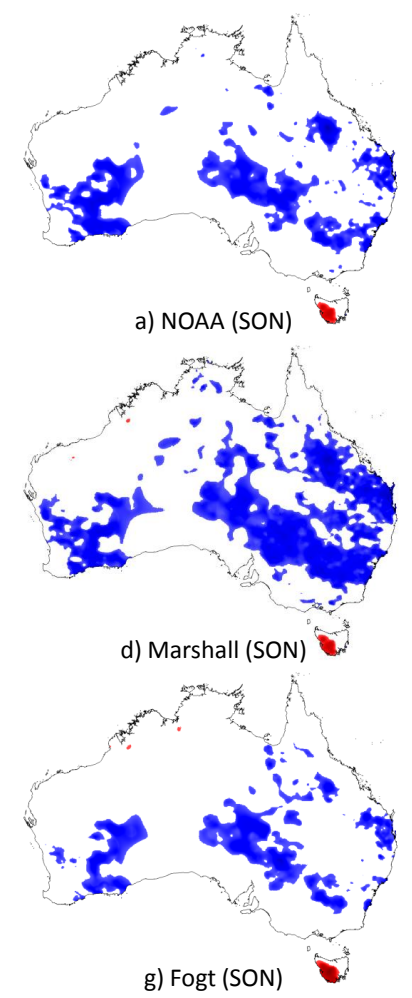
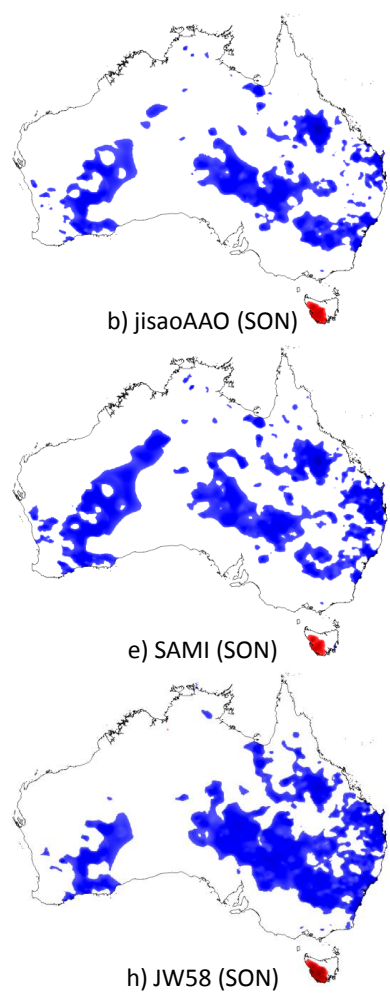

h) JW58 (SON)
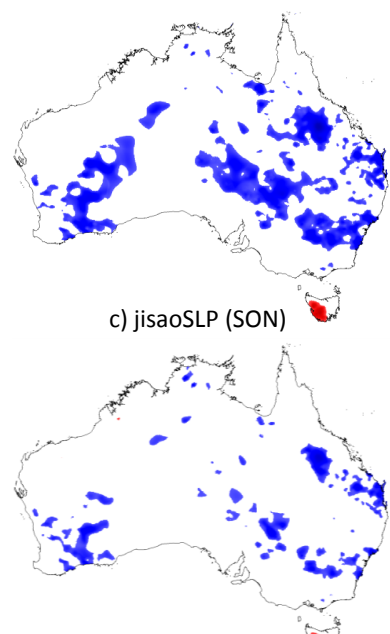

f) Visbeck (SON)

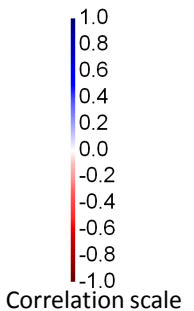

Fig. 7. Correlations between total spring (SON) rainfall and spring SAM indices, 1979-2002 (a) NOAA; (b) jisaoAAO; (c) jisaoSLP; (d) Marshall; (e) SAMI; (f) Visbeck; (g) Fogt and (h) JW58. Note: only correlations that are statistically significant at the 95th percentile are shown.

as occurring in winter instead of summer due to winter reanalysis data being particularly poor (Marshall, 2003). Section 5.2 also revealed considerable differences in the stationbased Visbeck and Marshall SAM indices when they were recalculated using either of the reanalysis data sets. These results demonstrate the importance of ensuring that any associations identified in climate attributions studies are real and not just an artefact of the data sets or methods being employed. Also highlighted is the fact that reanalysis data is effectively modelled data and relationships obtained using reanalysis based SAM indices should be verified with observational (i.e. station based) data, particularly prior to the assimilation of satellite data (i.e. pre-1979) when the reanalysis based SAM indices are likely to be flawed.

SAM indices based on station records of pressure at $40^{\circ} \mathrm{S}$ and $65^{\circ} \mathrm{S}$ are most likely to have the most accurate representation of SAM prior to 1979 , but are limited to periods when good quality stations are available. The Visbeck and Marshall indices are both developed using station based data as opposed to reanalysis data. In the case of the Visbeck index, the issue of limited data is partially resolved through the use of reconstructed pressure readings, which introduces another source of uncertainty (Visbeck, 2009). The results in Sect. 5.1 (Table 2, Figs. 1 and 2) indicate that the Visbeck and Marshall indices are not dissimilar to each other or to the reanalysis-based representations of SAM (correlations of about 0.9 in all cases) that were previously mentioned as being realistic (i.e. NOAA, jisaoSLP, jisaoAAO and SAMI). However, the results in Sect. 5.3 clearly illustrate that these minor differences in station-based and reanalysisbased indices result in marked inconsistencies in the magnitude and spatial pattern of the SAM relationship with Australian rainfall.

Additionally, both Fogt and JW58 indices showed marked differences from all other indices. Both were developed with a view to investigating long term SAM variability. Both the methods and data sets used to develop these indices are likely to have resulted in their dissimilarity over the period of analysis used in this paper.

Therefore, which SAM index is recommended for hydroclimatic attribution studies in Australia? While there is a strong desire in the hydroclimatic community for a single SAM index to be identified that is most reflective of SAM behaviour what this study highlights is that this is unlikely to be possible. This study has categorically shown that all SAM indices are different and that these differences come from a number of sources as summarised in Table 1 (e.g. definition method, source data, variable, time period, temporal scale). This study does not claim to provide any evidence that any SAM index is more flawed or more correct than any other 


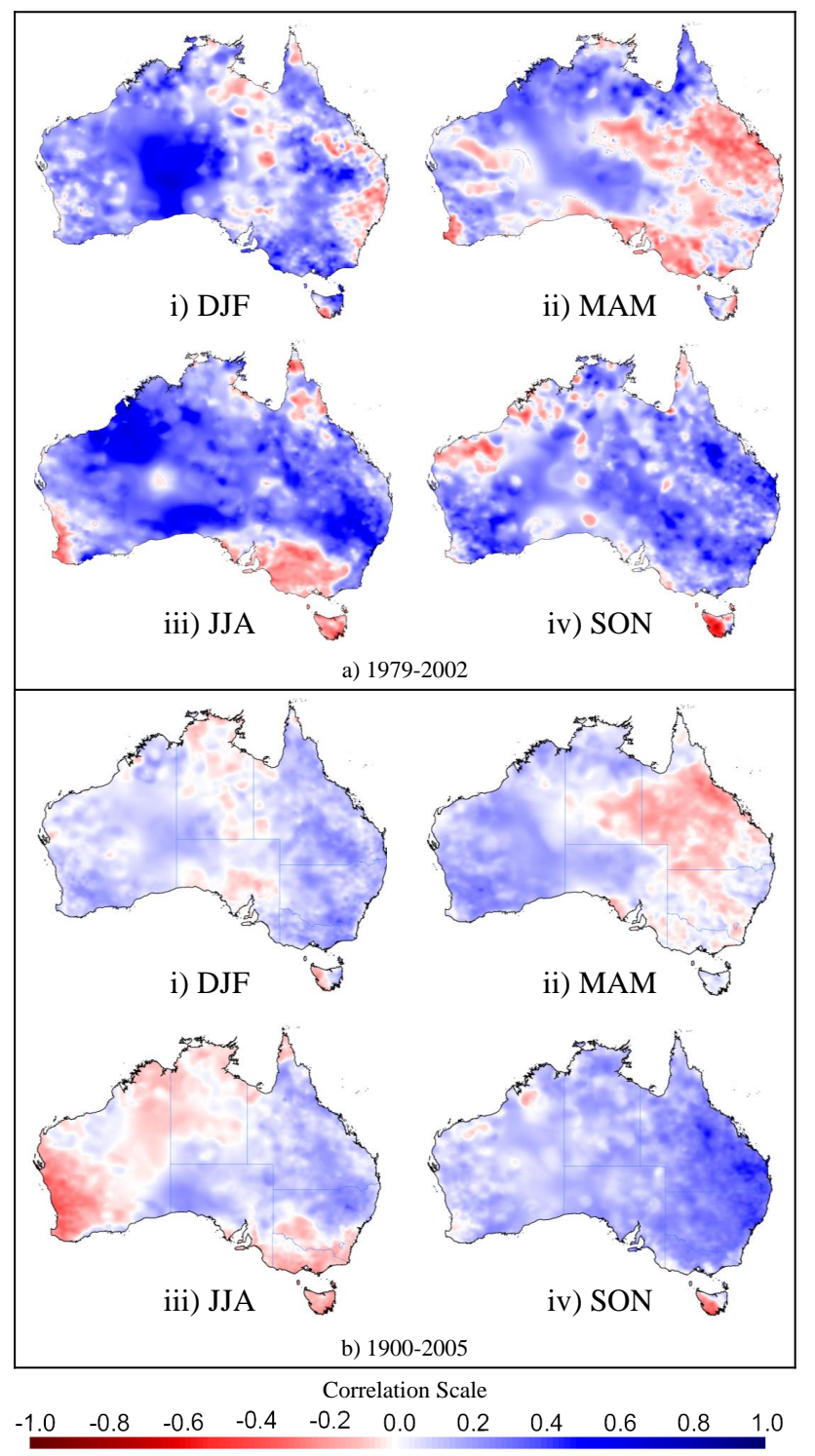

Fig. 8. Seasonal Australian rainfall correlated with Visbeck over (a) 1979-2002 and (b) 1900-2005 for (i) DJF, (ii) MAM, (iii) JJA and (iv) SON.

but rather that the most appropriate index will depend on the intended application (e.g. is information required pre-1979 or even pre-1950s?, is high spatial resolution important?, is monthly data required or is seasonal sufficient? etc.). Nevertheless, given the results presented in this paper and especially considering the issues associated with SAM representation in the reanalysis data (Marshall, 2003), our recommendation is that the Marshall or Visbeck station-based SAM indices are most reliable for hydroclimatic investigations in the period prior to the widespread availability of satellite data (i.e. pre-1979). Given the uncertainties associated with the reconstructed pressure readings in the Visbeck index our recommendation is to use the Marshall index when it exists
(1957-2011), as it uses a consistent network of station data, and the Visbeck index if analyses are required prior to that. Post-1978 (i.e. since satellite data has become available) the reanalysis based SAM indices are similar to Marshall and Visbeck but as suggested by Fig. 4 to Fig. 7 the small differences in SAM index values can still lead to marked uncertainties when trying to relate SAM behaviour to Australian hydroclimatic variability and it is important that this uncertainty is acknowledged and quantified such that erroneous associations are not made.

Following on from that, and with respect to the question as to the true relationship between SAM and Australian rainfall - i.e. question (b), it should be noted that for all seasons there are large areas where the correlations between SAM and Australian rainfall are not statistically significant. However, it should also be recognised that the lack of a significant correlation does not neccessarily mean that there is no relationship between SAM and Australian rainfall. It just may be that the relationship is non-linear, non-stationary or modulated by other factors (Hendon et al., 2007; Verdon-Kidd and Kiem, 2009b; Gallant et al., 2011). Therefore, further investigation is required into the non-linear, and potentially non-stationary, nature of SAM impacts and novel methods need to be developed to gain insights into how SAM is related to, or interacts with, other large-scale (e.g. ENSO, IOD, IPO) climate drivers and local-scale weather patterns known to influence Australian hydroclimatology - i.e. question (c) posed above.

Climate indices are a practical way of approximating large-scale climate phenomena. The climate indices can then be used in empirical studies aimed at improving our understanding into the causal processes behind observed hydroclimatic variability. However, this is only suitable if (a) the index is a realistic approximation of the climate process and (b) the empirical relationships developed using the index are physically real. It is important to realise that all indices are approximations and the "best" index, if there is such a thing, will depend on what you are using the index for (Kiem and Franks, 2001). Importantly, this study has highlighted that it is crucial to be aware of the differences in the various SAM indices and to consider the fact that insights gained using climate index based analysis could be just an artefact of the index chosen (this applies equally to indices of climate modes other than SAM). It is critical to consider and account for this uncertainty in any climate impact attribution study and also in climate model verification and performance assessments if misunderstandings are to be avoided. It is also questioned whether it is sensible to assume that an index based on a single variable can ever be truly representative of the SAM process or whether more comprehensive multivariate or regional monitors of the SAM state are required. Perhaps something similar to the Multivariate ENSO Index (MEI, Wolter and Timlin, 1993, 1998), which has been shown to more realistically and more consistently capture the entire ENSO phenomenon and its related impacts in Australia (e.g. Kiem and 
Franks, 2001), or the concept of a regional index similar to that used by Meneghini et al. (2007), could be explored.

Acknowledgements. MH is supported by the Australian Postgraduate Award with additional assistance from a CSIRO Land \& Water Flagship Scholarship and a NCCARF Water Network Scholarship. The authors would like to thank Julie Jones from the University of Sheffield for her provision of her reconstructed SAM index and Martin Visbeck from IFM-GEOMAR, Kiel, Germany for data clarifications, calculation software and provision of the monthly Visbeck index. We would like to thank the two anonymous reviewers and the handling editor for their constructive comments and suggestions that have improved this paper.

Edited by: W. Buytaert

\section{References}

Barnes, S. L.: Mesoscale objective map analysis using weighted time-series of observations. NOAA Technical Memorandum, ERL NSSL, 62, NTIS COM-73-10781, National Severe Storms Laboratory, Norman, OK, p. 60, 1973.

Cai, W. and Cowan, T.: SAM and regional rainfall in IPCC AR4 models: Can anthropogenic forcing account for southwest Western Australian winter rainfall reduction?, Geophys. Res. Lett., 33, L24708, doi:10.1029/2006GL028037, 2006.

Cai, W., Shi, G., Cowan, T., Bi, D., and Ribbe, J.: The response of the Southern Annular Mode, the East Australian Current, and the southern mid-latitude ocean circulation to global warming, Geophys. Res. Lett., 32, L23706, doi:10.1029/2005GL024701, 2005.

Chiew, F. H. S., Piechota, T. C., Dracup, J. A., and McMahon, T. A.: El Niño/Southern Oscillation and Australian rainfall, streamflow and drought: Links and potential for forecasting, J. Hydrol., 204, 138-149, 1998.

Drosdowsky, W.: An analysis of Australian seasonal rainfall anomalies: 1950-1987, II: Temporal variability and teleconnection patterns, Int. J. Climatol., 13, 111-149, doi:10.1002/joc.3370130202, 1993.

Fan, K. and Wang, H.: Antarctic oscillation and the dust weather frequency in North China, Geophys. Res. Lett., 31, L10201, doi:10.1029/2004GL019465, 2004.

Feng, J., Li, J., and Li, Y.: Is There a Relationship between the SAM and Southwest Western Australian Winter Rainfall?, J. Climate, 23, 6082-6089, doi:10.1175/2010jcli3667.1, 2010.

Franks, S. W. and Kuczera, G.: Flood frequency analysis: Evidence and implications of secular climate variability, New South Wales, Water Resour. Res., 38, 1062, doi:10.1029/2001WR000232, 2002.

Gallant, A. J. E., Kiem, A. S., Verdon-Kidd, D. C., Stone, R. C., and Karoly, D. J.: Understanding climate processes in the Murray-Darling Basin: utility and limitations for natural resources management, Hydrol. Earth Syst. Sci. Discuss., 8, 78737918, doi:10.5194/hessd-8-7873-2011, 2011.

Gillett, N. P., Kell, T. D., and Jones, P. D.:Regional climate impacts of the Southern Annular Mode, Geophys. Res. Lett., 33, L23704, doi:10.1029/2006GL027721, 2006.

Gong, D. and Wang, S.: Antarctic oscillation: concept and applications, Chinese Sci. Bull., 43, 734-738, 1998.
Gong, D. and Wang, S.: Definition of Antarctic oscillation index, Geophys. Res. Lett., 26, 459-462, doi:10.1029/1999GL900003, 1999.

Goodwin, I. D., van Ommen, T. D., Curran, M. A. J., and Mayewski, P. A.: Mid latitude winter climate variability in the South Indian and southwest Pacific regions since 1300 AD, Clim. Dynam., 22, 783-794, doi:10.1007/s00382-004-0403-3, 2004.

Hendon, H. H., Thompson, D. W. J., and Wheeler, M. C.: Australian Rainfall and Surface Temperature Variations Associated with the Southern Hemisphere Annular Mode, J. Climate, 20, 2452-2467, doi:10.1175/JCLI4134.1, 2007.

Jones, D. A., Wang, W., and Fawcett, R.: High-quality spatial climate data-sets for Australia, Aust. Meteorol. Oceanogr. J., 58, 233-248, 2009.

Jones, J. M. and Widmann, M.: Atmospheric science: Early peak in Antarctic oscillation index, Nature, 432, 290-291, 2004.

Jones, J. M., Fogt, R. L., Widmann, M., Marshall, G. J., Jones, P. D., and Visbeck, M.: Historical SAM Variability, Part I: CenturyLength Seasonal Reconstructions, J. Climate, 22, 5319-5345, doi:10.1175/2009JCLI2785.1, 2009.

Karoly, D. J., Hope, P., and Jones, P. D.: Decadal Variations of the Southern Hemisphere Circulation, Int. J. Climatol., 16, 723-738, 1996.

Kidson, J. W. and Sinclair, M. R.: The Influence of Persistent Anomalies on Southern Hemisphere Storm Tracks, J. Climate, 8, 1938-1950, doi:10.1175/15200442(1995)008<1938:tiopao>2.0.co;2, 1995.

Kidson, J. W. and Watterson, I. G.: The Structure and Predictability of the "High-Latitude Mode" in the CSIRO9 General Circulation Model, J. Atmos. Sci., 56, 3859-3873, doi:10.1175/15200469(1999)056<3859:tsapot>2.0.co;2, 1999.

Kidston, J., Renwick, J. A., and McGregor, J.: HemisphericScale Seasonality of the Southern Annular Mode and Impacts on the Climate of New Zealand, J. Climate, 22, 4759-4770, doi:10.1175/2009jcli2640.1, 2009.

Kiem, A. S. and Franks, S. W.: On the identification of ENSOinduced rainfall and runoff variability: a comparison of methods and indices, Hydrolog. Sci. J., 46, 715-727, 2001.

Kiem, A. S. and Franks, S. W.: Multi-decadal variability of drought risk, eastern Australia, Hydrol. Process., 18, 2039-2050, doi:10.1002/hyp.1460, 2004.

Kiem, A. S., Franks, S. W., and Kuczera, G.: Multi-decadal variability of flood risk, Geophys. Res. Lett., 30, 1035, doi:10.1029/2002GL015992, 2003.

Kiem, A. S. and Verdon-Kidd, D. C.: Towards understanding hydroclimatic change in Victoria, Australia - preliminary insights into the "Big Dry", Hydrol. Earth Syst. Sci., 14, 433-445, doi:10.5194/hess-14-433-2010, 2010.

Kiem, A. S. and Verdon-Kidd, D. C.: Steps toward "useful" hydroclimatic scenarios for water resource management in the Murray-Darling Basin, Water Resour. Res., 47, W00G06, doi:10.1029/2010wr009803, 2011.

King, J. C. and Turner, J.: Antarctic meteorology and climatology, Cambridge University Press, Cambridge, UK, 2007.

L'Heureux, M. L. and Thompson, D. W. J.: Observed Relationships between the El Niño Southern Oscillation and the Extratropical Zonal-Mean Circulation, J. Climate, 19, 276-287, doi:10.1175/jcli3617.1, 2006. 
Limpasuvan, V. and Hartmann, D. L.: Eddies and the annular modes of climate variability, Geophys. Res. Lett., 26, 31333136, doi:10.1029/1999g1010478, 1999.

Marshall, G. J.: Trends in the Southern Annular Mode from Observations and Reanalyses, J. Climate, 16, 4134-4143, 2003.

Marshall, G. J.: Half-century seasonal relationships between the Southern Annular mode and Antarctic temperatures, Int. J. Climatol., 27, 373-383, doi:10.1002/joc.1407, 2007.

McBride, J. L. and Nicholls, N.: Seasonal Relationships between Australian Rainfall and the Southern Oscillation, Mon. Weather Rev., 111, 1998-2004, 1983.

Meneghini, B., Simmonds, I., and Smith, I. N.: Association between Australian rainfall and the Southern Annular Mode, Int. J. Climatol., 27, 109-121, 2007.

Meyers, G., McIntosh, P., Pigot, L., and Pook, M.: The Years of El Niño, La Niña, and Interactions with the Tropical Indian Ocean, J. Climate, 20, 2872-2880, 2007.

Murphy, B. F. and Timbal, B.: A review of recent climate variability and climate change in southeastern Australia, Int. J. Climatol., 28, 859-879, 2008.

Nan, S. and Li, J.: The relationship between the summer precipitation in the Yangtze River valley and the boreal spring Southern Hemisphere annular mode, Geophys. Res. Lett., 30, 2266. doi:10.1029/2003GL018381, 2003.

Nicholls, N.: The Changing Nature of Australian Droughts, Climatic Change, 63, 323-336, 2004.

Power, S., Casey, T., Folland, C., Colman, A., and Mehta, V.: Interdecadal modulation of the impact of ENSO on Australia, Clim. Dynam., 15, 319-324, 1999.

Reason, C. J. C. and Rouault, M.: Links between the Antarctic Oscillation and winter rainfall over western South Africa, Geophys. Res. Lett., 32, L07705, doi:10.1029/2005GL022419, 2005.

Risbey, J. S., Pook, M. J., McIntosh, P. C., Wheeler, M. C., and Hendon, H.H.: On the Remote Drivers of Rainfall Variability in Australia, Mon. Weather Rev., 137, 3233-3253, 2009.

Rogers, J. C. and van Loon, H.: Spatial Variability of Sea Level Pressure and $500 \mathrm{mb}$ Height Anomalies over the Southern Hemisphere, Mon. Weather Rev., 110, 1375-1392, 1982.

Saji, N. H. and Yamagata, T.: Possible impacts of Indian Ocean Dipole mode events on global climate, Clim. Res., 25, 151-169, 2003.
Silvestri, G. and Vera, C.: Nonstationary Impacts of the Southern Annular Mode on Southern Hemisphere Climate, J. Climate, 22, 6142-6148, doi:10.1175/2009jcli3036.1, 2009.

Simmonds, I. and Keay, K.: Variability of Southern Hemisphere Extratropical Cyclone Behavior, 1958-97, J. Climate, 13, 550561, doi:10.1175/1520-0442(2000)013<0550:voshec > 2.0.co;2, 2000.

Sturman, A. and Tapper, N.: The weather and climate of Australia and New Zealand, Oxford University Press, South Melbourne, 2006.

Thompson, D. W. J. and Wallace, J. M.: The Arctic oscillation signature in the wintertime geopotential height and temperature fields, Geophys. Res. Lett., 25, 1297-1300, doi:10.1029/98GL00950, 1998.

Thompson, D. W. J. and Wallace, J. M.: Annular Modes in the Extratropical Circulation, Part I: Month-to-Month Variability, J. Climate, 13, 1000-1016, 2000.

Verdon, D. C. and Franks, S. W.: Indian Ocean sea surface temperature variability and winter rainfall: Eastern Australia, Water Resour. Res., 41, W09413, doi:10.1029/2004WR003845, 2005.

Verdon, D. C., Wyatt, A. M., Kiem, A. S., and Franks, S. W.: Multidecadal variability of rainfall and streamflow: Eastern Australia, Water Resour. Res., 40, W10201. doi:10.1029/2004WR003234, 2004.

Verdon-Kidd, D. C. and Kiem, A. S.: Nature and causes of protracted droughts in southeast Australia: Comparison between the Federation, WWII, and Big Dry droughts, Geophys. Res. Lett., 36, 1-6, doi:10.1029/2009GL041067, 2009a.

Verdon-Kidd, D. C. and Kiem, A. S.: On the relationship between large-scale climate modes and regional synoptic patterns that drive Victorian rainfall, Hydrol. Earth Syst. Sci., 13, 467-479, doi:10.5194/hess-13-467-2009, 2009b.

Visbeck, M.: A Station-Based Southern Annular Mode Index from 1884 to 2005, J. Climate, 22, 940-950, doi:10.1175/2008JCLI2260.1, 2009.

Wolter, K. and Timlin, M. S.: Monitoring ENSO in COADS with a seasonally adjusted principal component index, Proc. 17th Climate Diagnostics Workshop, Norman, Oklahoma, 52-57, 1993.

Wolter, K. and Timlin, M. S.: Measuring the strength of ENSO events: How does 1997/98 rank?, Weather, 53, 315-324, 1998. 